\title{
Characterization of a Primate Blood-Brain Barrier Co-Culture Model Prepared from Primary Brain Endothelial Cells, Pericytes and Astrocytes
}

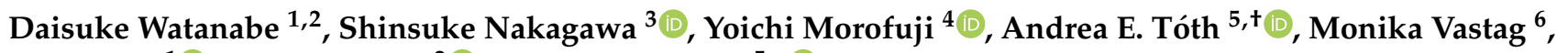 \\ Jun Aruga ${ }^{1}$, Masami Niwa ${ }^{2}$ and Mária A. Deli ${ }^{5, *(D)}$ \\ 1 Department of Medical Pharmacology, Nagasaki University Graduate School of Biomedical Sciences, \\ 1-12-4 Sakamoto, Nagasaki 852-8523, Japan; watanabe@pharmacocell.co.jp (D.W.); \\ aruga@nagasaki-u.ac.jp (J.A.) \\ 2 BBB Laboratory, PharmaCo-Cell Co., Ltd., Nagasaki 852-8135, Japan; niwa@pharmacocell.co.jp \\ 3 Department of Pharmaceutical Care and Health Sciences, Faculty of Pharmaceutical Sciences, \\ Fukuoka University, 8-19-1 Nanakuma, Jonan-ku, Fukuoka 814-0180, Japan; shin3@fukuoka-u.ac.jp \\ 4 Department of Neurosurgery, Nagasaki University Graduate School of Biomedical Sciences, \\ 1-7-1 Sakamoto, Nagasaki 852-8501, Japan; morofujiyoichi@gmail.com \\ 5 Institute of Biophysics, Biological Research Centre, Temesvári krt. 62, H-6726 Szeged, Hungary; \\ toth@biomed.au.dk \\ 6 In Vitro Metabolism Research, Division of Pharmacology and Drug Safety Research, Gedeon Richter Plc., \\ Gyömrői út 19-21, H-1103 Budapest, Hungary; m.vastag@richter.hu \\ * Correspondence: deli.maria@brc.hu \\ updates \\ + Current address: Department of Biomedicine, Faculty of Health, Aarhus University, \\ DK-8000 Aarhus, Denmark.
}

Citation: Watanabe, D.; Nakagawa, S.; Morofuji, Y.; Tóth, A.E.; Vastag, M.; Aruga, J.; Niwa, M.; Deli, M.A. Characterization of a Primate Blood-Brain Barrier Co-Culture Model Prepared from Primary Brain Endothelial Cells, Pericytes and Astrocytes. Pharmaceutics 2021, 13, 1484. https://doi.org/10.3390/ pharmaceutics13091484

Academic Editor: Tomáš Etrych

Received: 28 July 2021

Accepted: 13 September 2021

Published: 16 September 2021

Publisher's Note: MDPI stays neutral with regard to jurisdictional claims in published maps and institutional affiliations.

Copyright: (c) 2021 by the authors. Licensee MDPI, Basel, Switzerland. This article is an open access article distributed under the terms and conditions of the Creative Commons Attribution (CC BY) license (https:/ / creativecommons.org/licenses/by/ $4.0 /)$.
Abstract: Culture models of the blood-brain barrier (BBB) are important research tools. Their role in the preclinical phase of drug development to estimate the permeability for potential neuropharmaceuticals is especially relevant. Since species differences in BBB transport systems exist, primate models are considered as predictive for drug transport to brain in humans. Based on our previous expertise we have developed and characterized a non-human primate co-culture BBB model using primary cultures of monkey brain endothelial cells, rat brain pericytes, and rat astrocytes. Monkey brain endothelial cells in the presence of both pericytes and astrocytes (EPA model) expressed enhanced barrier properties and increased levels of tight junction proteins occludin, claudin-5, and ZO-1. Co-culture conditions also elevated the expression of key BBB influx and efflux transporters, including glucose transporter-1, MFSD2A, ABCB1, and ABCG2. The correlation between the endothelial permeability coefficients of 10 well known drugs was higher $\left(R^{2}=0.8788\right)$ when the monkey and rat $\mathrm{BBB}$ culture models were compared than when the monkey culture model was compared to mouse in vivo data $\left(R^{2}=0.6619\right)$, hinting at transporter differences. The applicability of the new non-human primate model in drug discovery has been proven in several studies.

Keywords: blood-brain barrier; brain endothelial cell; astrocyte; pericyte; co-culture; transporter; transendothelial electrical resistance; drug permeability

\section{Introduction}

Cell-culture based models have greatly contributed to our knowledge on the physiology, pathology, and pharmacology of the blood-brain barrier (BBB) [1-3]. In the preclinical phase of drug development, it is key to estimate the brain penetration of potential neuropharmaceuticals, and in this process culture models of the BBB are essential tools [2,4-6]. The specific features of cerebral capillary endothelial cells, which form the anatomical basis of the BBB, are organ specific. The dynamic interactions between brain endothelial cells and the neighboring astrocytes and pericytes promote the development and maintenance of BBB functions $[7,8]$. It is therefore crucial to mimic this cellular complexity and the crosstalk 
between these three cell types in culture models of the BBB. The first co-culture models, developed in the end of 1980s, were based on cerebral endothelial cells grown in the presence of astrocytes. These well characterized models are still used for drug permeability and discovery studies [1-3]. We have demonstrated that not only astrocytes, but brain pericytes can also increase the tightness of the paracellular barrier of rat brain endothelial cells in culture [9]. Based on this observation we have pioneered a triple co-culture model of the BBB using primary rat brain endothelial cells, pericytes, and astrocytes [10]. The number of triple co-culture BBB models from different species and cell sources, including primary cells, cell lines, and stem-cell derived cells, has been expanded in the last decade [3].

While the basic defense mechanisms and functions of the BBB are well conserved in mammals, species differences have been described in BBB transport systems. Using quantitative proteomics, the expression of active efflux and influx transporters in human brain capillaries were close to those from monkey, but more different as compared to mouse brain capillaries [11,12], indicating the limitations of the widely used rodent models. While the best models for the prediction of brain penetration of pharmaceutics in patients would be human cell-based systems, the current human BBB models have several weak points. The expression of tight junction proteins and the paracellular barrier of human brain endothelial cell lines is not tight enough for testing small molecules [3,6]. The paracellular tightness of the stem cell based human BBB models is much stronger, and high electrical resistance values were described [3], but some of these models do not show a typical endothelial cytoarchitecture [13]. Primary brain endothelial cells have both appropriate barrier tightness and microvascular endothelial characteristics $[1,3,5,6,8]$. The reproducibility of co-culture BBB models is usually good within laboratories, but the properties of models may differ between different groups [1,3].

Our aim was to develop a new primate co-culture BBB model using primary cultures of monkey brain capillary endothelial cells, rat pericytes and rat astrocytes, characterize its paracellular barrier properties, and demonstrate the presence of selected key BBB transporters. To assess the model's applicability for drug transport studies we tested the permeability of 10 well-known pharmacons and compared the data with results obtained on a rat triple co-culture model and brain penetration in mice.

\section{Materials and Methods}

\subsection{Animals}

Wistar rats were obtained from Japan SLC Inc. (Shizuoka, Japan). Rats were housed under specific pathogen-free conditions in an air-conditioned room and fed standard laboratory chow ad libitum, in accordance with institutional guidelines. Based on the Guide for the Care and Use of Laboratory Animals from the Ministry of Education, Culture, Sports, Science, and Technology, Japan, all experimental procedures were reviewed by Institutional Animal Care and Use Committee of Nagasaki University and finally approved by the University's president (license no.: 1805011452, date of approval: 1 May 2018). Brains from cynomolgus monkeys (Macaca fascicularis) were purchased and transported from Ina Research Inc. (Nagano, Japan) to the laboratory in cold phosphate-buffered saline (PBS) with $\mathrm{Ca}^{2+}$ and $\mathrm{Mg}^{2+}$ (Wako Pure Chemical Industries, Ltd., Osaka, Japan) supplemented with amphotericin B solution $(2.5 \mu \mathrm{g} / \mathrm{mL})$ within $24 \mathrm{~h}$. The animals were tested for antibodies to herpes B-virus, Shigella, Salmonella, and tuberculosis and showed negative results on screening.

\subsection{Materials and Reagents}

All reagents used in the study were purchased from Sigma (St. Louis, MO, USA), unless otherwise indicated.

\subsection{Primary Cell Cultures}

Primary cultures of monkey brain capillary endothelial cells (MBECs) and astrocytes were prepared from 3 to 5-year-old male Macaca fascicularis monkeys. The preparation of 
primary cultures of MBECs were based on our previously described method for rat brain endothelial cells $[9,10]$. Briefly, meninges and surface vessels were removed, and gray matter was minced into small pieces. The minced gray matter was digested in a mixture of collagenase type $2(340 \mathrm{U} / \mathrm{mL}$, Worthington, OH, USA), and DNase $(15 \mu \mathrm{g} / \mathrm{mL})$ for $1.5 \mathrm{~h}$ at $37^{\circ} \mathrm{C}$. The cell pellet was separated by centrifugation in $20 \%$ bovine serum albumin (BSA)$\operatorname{DMEM}(1000 \times g, 25 \mathrm{~min})$. The microvessels obtained in the pellet were further digested with collagenase-dispase $(1 \mathrm{mg} / \mathrm{mL}$, Roche, Basel, Switzerland) and DNase $(6.7 \mu \mathrm{g} / \mathrm{mL})$ in $15 \mathrm{~mL}$ of DMEM for $45 \mathrm{~min}$ at $37^{\circ} \mathrm{C}$. Microvessel endothelial cell clusters were separated on a 33\% continuous Percoll gradient at $1000 \times g$ for $10 \mathrm{~min}$. A white color layer, above the red layer consisting of red blood cells near the bottom of the tube, contained the microvessel fragments. The microvessel fragments were collected, washed in DMEM, and plated on plastic dishes coated with collagen type IV and fibronectin (both $0.1 \mathrm{mg} / \mathrm{mL}$ ). MBEC cultures were maintained in DMEM/F12 supplemented with 10\% plasma-derived serum (PDS, Animal Technologies, Tyler, TX, USA), basic fibroblast growth factor (bFGF, Roche, Switzerland, $1.5 \mathrm{ng} / \mathrm{mL})$, heparin $(100 \mu \mathrm{g} / \mathrm{mL})$, insulin $(5 \mu \mathrm{g} / \mathrm{mL})$, transferrin $(5 \mu \mathrm{g} / \mathrm{mL})$, sodium selenite ( $5 \mathrm{ng} / \mathrm{mL}$ ) (insulin-transferrin-sodium selenite media supplement), and gentamicin $(50 \mu \mathrm{g} / \mathrm{mL})$. During the first 2 days of culture, the medium of endothelial cells also contained $4 \mu \mathrm{g} / \mathrm{mL}$ puromycin to eliminate P-glycoprotein negative, contaminating cell types [14]. When MBEC cultures were confluent, cells were trypsinized, seeded to culture inserts, and used for experiments at passage 1.

Monkey astrocytes were isolated from a piece of gray matter. The gray matter was mechanically dissociated and digested with papain $(1 \mathrm{mg} / \mathrm{mL})$. Dissociated cells were seeded in cell culture flasks coated with poly-L-lysine. Cells were maintained in DMEM supplemented with 10\% fetal bovine serum (FBS). After 2 weeks, flasks with confluent cultures were shaken to obtain pure astrocyte culture.

Rat brain endothelial cells (RBECs) were isolated from male Wistar rats (3 to 4 weeks old). RBECs were isolated and cultured using the method described for MBECs. Rat cerebral astrocytes and pericytes were obtained from neonatal rats and 3-week-old male rats, respectively, as we described previously $[9,10]$ (see Supplementary Methods). Both pericytes and astrocytes were cultured in DMEM medium supplemented with 10\% FBS and used at passages 2 or 3 .

\subsection{Construction of the BBB Model}

To prepare the in vitro co-culture models (EPA), pericytes $\left(2 \times 10^{4}\right.$ cells $\left./ \mathrm{cm}^{2}\right)$ were cultured on the bottom sides of collagen-coated culture inserts (Transwell clear, polyester membrane, $0.4 \mu \mathrm{m}$ pore size, Corning Costar, NY, USA), and astrocytes $\left(0.5 \times 10^{5} \mathrm{cell} / \mathrm{cm}^{2}\right)$ were seeded on the collagen-coated well of a 24-well culture plate. Cells were let to adhere overnight, and endothelial cells $\left(2 \times 10^{5}\right.$ cells $\left./ \mathrm{cm}^{2}\right)$ were seeded on the inside of the inserts (top side of the membranes) and placed in the wells of the 24-well culture plates. An endothelial cell monolayer model (E00) was constructed by a similar method as the coculture model, except for the procedure of seeding of pericytes and astrocytes. BBB models were maintained in RBEC medium supplemented with $550 \mathrm{nM}$ hydrocortisone $[10,14]$.

\subsection{Immunohistochemistry}

For immunohistochemical characterization, MBECs were stained with anti-claudin-5, occludin, ZO-1 (Invitrogen Corporation, Waltham, MA, USA), or von Willebrand factor antibodies. Astrocytes were stained with anti-GFAP antibody (Progen Scientific Ltd., Mexborough, UK). All primary antibodies were used at a dilution of 1:100. As secondary antibodies Alexa Fluor 488 conjugated donkey anti-rabbit and anti-mouse immunoglobulins (both from Invitrogen Corporation) were used at a dilution of 1:1000. The source and catalogue number of antibodies is listed in Table S1. To counterstain cell nuclei TO-PRO-3 Iodide (Invitrogen Corporation) was used at a dilution of 1:400. Cultured cells were fixed in 3\% paraformaldehyde in PBS for 10 min and permeabilized with $0.1 \%$ Triton X-100 for $10 \mathrm{~min}$. Cells were blocked with 3\% bovine serum albumin and were incubated with 
primary antibodies overnight at $4{ }^{\circ} \mathrm{C}$. After washing, cells were incubated for $1 \mathrm{~h}$ at room temperature with secondary antibodies and TO-PRO-3. Cells were washed three times with PBS, and preparations were mounted with Gel Mount (Biomeda, Foster City, CA, USA) and staining was examined using a Zeiss LSM 5 Pascal Confocal laser scanning microscope (Carl Zeiss AG, Oberkochen, Germany).

\subsection{Reverse Transcription Polymerase CHAIN Reaction}

For analysis of expression of transporters on each BBB model cultured for four days, total RNA was isolated with a RNeasy Mini Kit (Qiagen, Hilden, Germany) according to the manufacturer's instructions. During RNA purification, genomic DNA was eliminated using RNase-Free DNase Set (Qiagen, Hilden, Germany). Concentration and purity (A260/280) of total RNA was analyzed by NanoDrop 1000 (Thermo Fisher Scientific, Waltham, MA, USA). First strand cDNA was synthesized from $1 \mu \mathrm{g}$ total RNA with the Reverse Transcription System (Promega, Madison, WI, USA). The generated cDNA was stored at $-20{ }^{\circ} \mathrm{C}$ until use. Polymerase chain reaction (PCR) fragments for transporters were amplified using the primer pairs shown in Table 1. The primers were designed using Primer-BLAST (NCBI, NIH, Bethesda MD, USA) and synthesized by Sigma-Genosys Ltd. Haverhill, UK. The specificity of each primer pair was verified by the appearance of a single band in agarose gels (Figure 2a) and a single peak in a melting curve (Figure S1). PCR was performed in a final volume of $20 \mu \mathrm{L}$ containing $0.5 \mu \mathrm{L}$ of template cDNA, $1.6 \mu \mathrm{L}$ of dNTP mixture, $2 \mu \mathrm{L}$ of $10 \times$ PCR buffer, 0.5 unit of Takara Taq ${ }^{\text {TM }}$ Hot Start Version polymerase (Takara Bio, Inc., Shiga, Japan), and $1 \mu \mathrm{M}$ of each primer, using a PCR Express II thermal cycler (Thermo Electron Corp., Waltham, MA, USA). PCR from the first strand cDNAs were performed with Takara Taq ${ }^{\mathrm{TM}}$ Hot Start Version (Takara Bio Inc., Shiga, Japan) and PCR Express II thermal cycler (Thermo Electron Corp., Waltham, MA, USA). PCR was performed with 40 cycles of denaturation at $98^{\circ} \mathrm{C}$ for $10 \mathrm{~s}$, annealing at $60{ }^{\circ} \mathrm{C}$ for $30 \mathrm{~s}$, and extension at $72{ }^{\circ} \mathrm{C}$ for $15 \mathrm{~s}$. PCR products were separated by electrophoresis on $1.5 \%$ agarose gels and stained with ethidium bromide. Real-time PCR amplifications were performed using the ABI PRISM 7900HT Sequence Detection System (Applied Biosystems, Waltham, MA, USA).

Table 1. Primers used for PCR analysis.

\begin{tabular}{|c|c|c|}
\hline Gene & Primer Sequence & Size (bp) \\
\hline ABCB1 (P-gp) & $\begin{array}{l}\text { F: GGCCTAAAGCCGAACACATTG } \\
\text { R: CTGAAGCACTGGGATGTCCA }\end{array}$ & 90 \\
\hline ABCG2 (BCRP) & $\begin{array}{l}\text { F: GCCACGGAGATCATAGAGCC } \\
\text { R: TCACCCCCGGAAAGTTGATG }\end{array}$ & 125 \\
\hline ABCC1 (MRP-1) & $\begin{array}{l}\text { F: CAAGGGATTGCCGTGTTTGG } \\
\text { R: AAGAAGCTCATGGGTGACCG }\end{array}$ & 116 \\
\hline ABCC2 (MRP-2) & $\begin{array}{l}\text { F: GCACAAGCAACTGCTCAACA } \\
\text { R: CCGTGGAAATATCACCGGCA }\end{array}$ & 104 \\
\hline ABCC4 (MRP-4) & $\begin{array}{l}\text { F: TCGCAATACCCTTGGTTCCC } \\
\text { R: CACTGGGCTCCGAGTTGTAG }\end{array}$ & 110 \\
\hline ABCC5 (MRP-5) & $\begin{array}{l}\text { F: CTTTGTCAAGGGCACACTGC } \\
\text { R: CCTGTGGGGGTTGTGTCAAA }\end{array}$ & 102 \\
\hline SLC2A1 (GLUT1) & $\begin{array}{l}\text { F: GAACTCTTCAGCCAGGGTCC } \\
\text { R: GGACCACATAGTTGCTCCAC }\end{array}$ & 116 \\
\hline SLC16A1 (MCT1) & $\begin{array}{l}\text { F: ACAAGTAAACGAGGCAGCGA } \\
\text { R: ACAAATATCGTTATAAGCGCGGA }\end{array}$ & 123 \\
\hline SLC7A5 (LAT1) & $\begin{array}{l}\text { F: CGTGAACTGCTACAGCGTGA } \\
\text { R: TTGGACACATCACCCTTCCC }\end{array}$ & 126 \\
\hline MFSD2a & $\begin{array}{l}\text { F: GCCCAGGTGAAGAAAGAACC } \\
\text { R: CACAGCCTGTCACCTGGTAG }\end{array}$ & 103 \\
\hline GAPDH & $\begin{array}{l}\text { F: CTCAAGATCGTCAGCAACGC } \\
\text { R: TCTTCTGGGTGGCAGTGATG }\end{array}$ & 130 \\
\hline
\end{tabular}


Each PCR was performed by mixing $1 \mu \mathrm{L}$ cDNA and 5 pmol of each primer (Table 1 ) with the THUNDERBIRD SYBR qPCR Mix (TOYOBO, Osaka, Japan). PCR reactions were as follows: $95{ }^{\circ} \mathrm{C}$ for $1 \mathrm{~min}, 40$ cycles at $95{ }^{\circ} \mathrm{C}$ for $15 \mathrm{~s}, 60{ }^{\circ} \mathrm{C}$ for $15 \mathrm{~s}$, and $72{ }^{\circ} \mathrm{C}$ for $45 \mathrm{~s}$. The cDNA quantities were measured in critical thresholds (CT) and normalized to GAPDH $(\triangle C T)$. The $\triangle C T$ values of the control were subtracted from each sample to gain the $\Delta \Delta C T$ values.

\subsection{Evaluation of the Barrier Integrity of the BBB Models}

To evaluate the barrier function in different BBB models, transendothelial electrical resistance (TEER) was measured by an EVOM resistance meter and Endohm chamber (World Precision Instruments, Sarasota, FL, USA). The resistance values of blank inserts (background resistance) were subtracted from values of inserts with cells. TEER data are shown as $\Omega \times \mathrm{cm}^{2}$. The permeability of sodium fluorescein (Na-F, MW: $376 \mathrm{Da}$ ) was also determined, and used as an index of paracellular transport. Cell culture inserts were transferred to 24-well plates containing $0.9 \mathrm{~mL}$ assay buffer (Dulbecco's PBS (D-PBS) containing $0.9 \mathrm{mM} \mathrm{CaCl}_{2}, 0.5 \mathrm{mM} \mathrm{MgCl}_{2}, 4.5 \mathrm{~g} / \mathrm{L}$ glucose, and $10 \mathrm{mM}$ HEPES; $\mathrm{pH}$ 7.4). The luminal culture medium was replaced with $0.2 \mathrm{~mL}$ of assay buffer containing $10 \mu \mathrm{g} / \mathrm{mL}$ $\mathrm{Na}-\mathrm{F}$. Fifteen or $45 \mathrm{~min}$ after Na-F addition, the inserts were transferred to new wells containing the assay buffer. Na-F concentration in the collected samples was measured using a multiwell spectrophotometer (Wallac 1420 ARVO Multiabel Counter; Perkin Elmer, Waltham, MA, USA; excitation wavelength: $485 \mathrm{~nm}$, emission wavelength: $535 \mathrm{~nm}$ ). Transendothelial permeability coefficient $\left(\mathrm{P}_{\mathrm{e}}\right)$ was calculated as previously described [10].

\subsection{Functional Assay for Efflux Transport}

The functional activity of P-glycoprotein (P-gp) was determined by measuring cellular accumulation and bidirectional transport of rhodamine 123 (R123), a ligand of P-gp. After washing with the same assay buffer used for permeability studies, the cells were incubated in assay buffer containing $5 \mu \mathrm{M}$ R123 for $1 \mathrm{~h}$. They were then washed twice with ice-cold D-PBS, and lysed in $0.2 \mathrm{~N} \mathrm{NaOH}$. The R123 content was determined using a multiwell spectrofluorometer (excitation wavelength: $485 \mathrm{~nm}$, emission wavelength: $535 \mathrm{~nm}$ ). Cellular protein was measured using the BCA protein assay kit (Pierce, Rockford, IL, USA). Cyclosporin $(10 \mu \mathrm{M}, 15 \mathrm{~min}$ preincubation) was used as a reference P-glycoprotein inhibitor. For bidirectional transport assay, the flux of $5 \mu \mathrm{M}$ R123 in assay buffer was measured for 1 $\mathrm{h}$ at $37^{\circ} \mathrm{C}$ in the luminal-to-abluminal and in the opposite abluminal-to-luminal directions. After measuring the R123 content in samples collected from both compartments, $\mathrm{P}_{\mathrm{e}}$ values were calculated.

\subsection{Drug Permeability Experiments}

The permeability of the same 10 drugs was measured in the apical-to-basolateral (A-B) and basolateral-to-apical (B-A) directions as described in our previous study [15]. All test compounds were dissolved in DMSO to yield a $10 \mathrm{mM}$ solution, which was further diluted to $10 \mu \mathrm{M}$ in HBSS-Hepes buffer (Hank's Buffered Salt Solution containing $25 \mathrm{mM}$ Hepes). The incubation time for each reference compound was as follows: $30 \mathrm{~min}$ for antipyrin, caffeine, verapamil, and indomethacin; $60 \mathrm{~min}$ for loperamide, quinidine, and digoxin; $120 \mathrm{~min}$ for cimetidine, atenolol, and vinblastine. The concentration of test compounds in the samples was determined by a Merck-Hitachi LaChrom HPLC with UV-VIS or a fluorescence detector (Merck, Darmstadt, Germany). Digoxin was measured on a Thermo LTQ XL linear ion trap mass spectrometer coupled with a Thermo Surveyor HPLC (San Jose, CA, USA). Apparent permeability coefficients $\left(\mathrm{P}_{\mathrm{app}}\right)$ were calculated using the following equation: Papp $=(\mathrm{dQ} / \mathrm{dT}) /\left(\mathrm{A} \times \mathrm{C}_{0}\right)$, where $\mathrm{dQ} / \mathrm{dT}$ is the cumulative amount in the receiver compartment versus time, $A$ is the surface of the filter, and $C_{0}$ is the initial concentration of the tracer in the luminal compartments. 


\subsection{Western Blotting}

Protein samples from brain endothelial cells cultured in the presence or absence of pericytes and astrocytes were harvested by scraping in radioimmunoprecipitation assay buffer (RIPA; Santa Cruz Biotechnology, Dallas, TX, USA). An equal amount of protein in each sample was separated on a 4-15\% Tris-Glycine eXtended gel (Bio-Rad, Hercules, CA, USA) and transferred onto Hybond ${ }^{\mathrm{TM}}-\mathrm{P}$ membranes (Amersham, Buckinghamshire, UK) which were incubated with anti-claudin-5, anti-occludin, and anti-ZO-1 antibodies at a dilution of 1:5000, anti-P-glycoprotein (GeneTex, Irvine, CA USA), anti-BCRP (Abnova, Taiwan), and anti-GLUT-1 (Abcam, Cambridge, UK) antibodies at a dilution of 1:2500, and anti- $\beta$-actin antibody (Sigma, loading control) at a dilution of 1:10,000 in 3\% BSA in PBS. The source and catalogue number of antibodies is listed in Table S1. To visualize the immunoreactive bands, blots were incubated in Clarity Max Western ECL Substrate (Bio-rad). The bands were detected using a FluorChem SP Imaging System (Alpha Innotech Corp., San Leandro, CA, USA).

\subsection{Statistical Analysis}

All data are expressed as the means \pm standard error of the mean (SEM). Statistical analysis of all data was determined using Student's $t$-test for two group comparisons, and analysis of variance followed by the Tukey-Kramer method for comparison of multiple groups. A $p$ value of less than 0.05 was considered statistically significant.

\section{Results}

\subsection{Characterization of Monkey Brain Endothelial Cells}

To characterize the morphology of primary MBEC cultures immunostaining was performed (Figure 1). The cells showed a spindle-shape morphology typical microvascular endothelial cultures and positive immunostaining for vWF, a marker for endothelial cells (Figure 1a). TJs formed between adjacent endothelial cells plays an important role in the restrictive property of the BBB. Immunostaining study revealed continuous and belt-like staining of the TJ proteins ZO-1 (Figure 1b), claudin-5 (Figure 1c), and occludin (Figure 1d) along the cell border in MBEC monolayers.
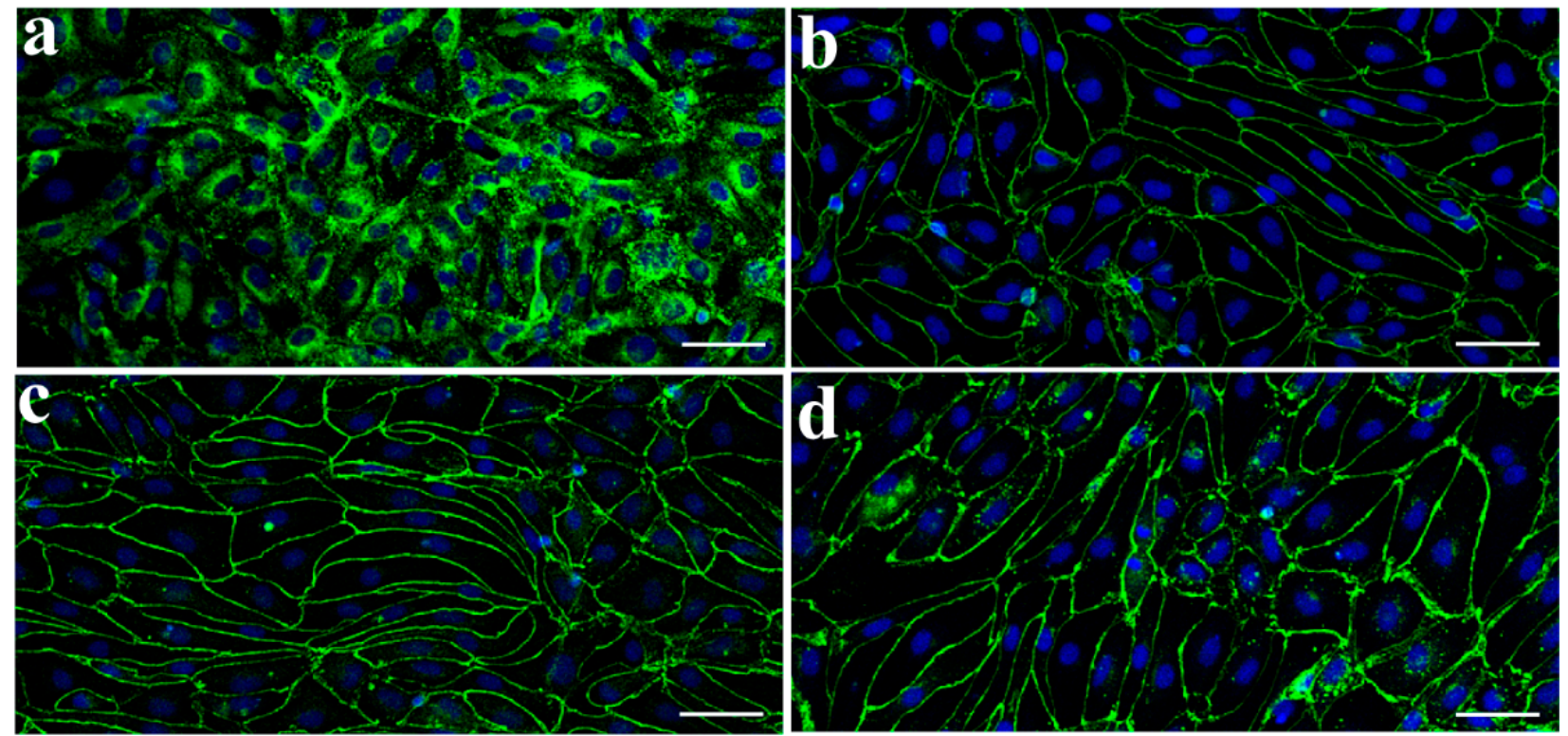

Figure 1. Characterization of primary monkey brain endothelial cells (MBECs) by immunofluorescence microscopy. MBECs express factor VIII-related antigen/von Willebrand factor (a). Tight junction protein ZO-1 (b), occludin (c), and claudin-5 (d) are expressed along the cell-cell border. Nuclear counterstain was stained with TO-PRO-3 (blue). Scale bar $=50 \mu \mathrm{m}$. 


\subsection{Expression of Transporters in Monkey Brain Endothelial Cells}

Brain capillary endothelial cells express several active efflux and influx transporters which contribute to the specific functions of the BBB. MBECs expressed mRNA for the efflux pumps P-gp (ABCB1), BCRP (ABCG2) and multidrug resistance-associated protein-1, 2,4 , and 5 (ABCC1, 2, 4, 5), as shown in Figure 2a. We also demonstrated the presence of nutrient transporters glucose transporter-1 (SLC2A1), monocarboxylate transporter-1 (SLC16A1), large neutral amino acids transporter-1 (SLC7A5), and the major facilitator superfamily domain containing protein-2A (MFSD2A) at gene level. The presence of the two most important $A B C$ efflux pumps, $\mathrm{P}$-gp and BCRP proteins, were verified by western blot both in monkey and rat primary BEC cultures (Figure 2b). The function of P-gp was further investigated by cellular uptake and bidirectional permeability studies using R123 (Figure 2c). A significant, more than three-fold increase, was measured in the intracellular accumulation of R123 in MBEC after treatment with cyclosporine A, an inhibitory substrate of P-gp (Figure 2c). P-gp expression is polarized in brain capillary endothelial cells, with a localization in the luminal membranes, facilitating the efflux of substrates from the brain side (basolateral) to the blood side (apical). In the bidirectional permeability assay, the transport of R123 from the brain side to the blood side was almost four-fold higher than in the opposite direction (Figure 2c) indicating a strong efflux pump activity.

$\boldsymbol{a}$

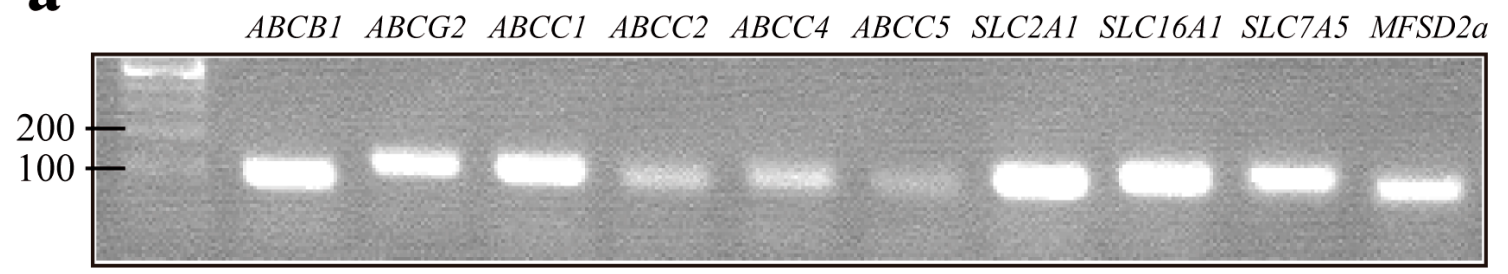

b

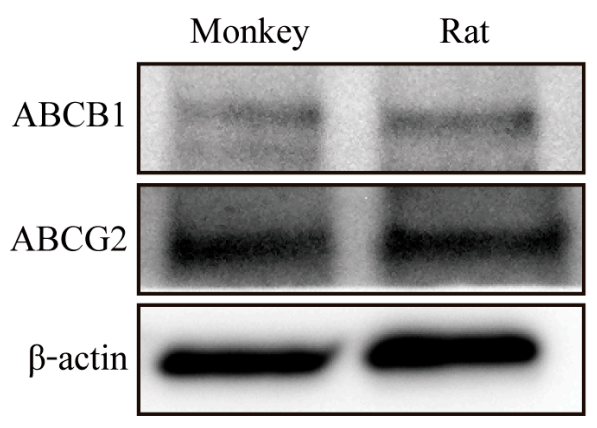

c

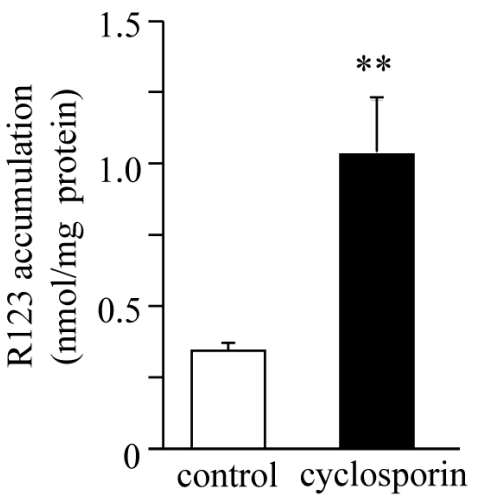

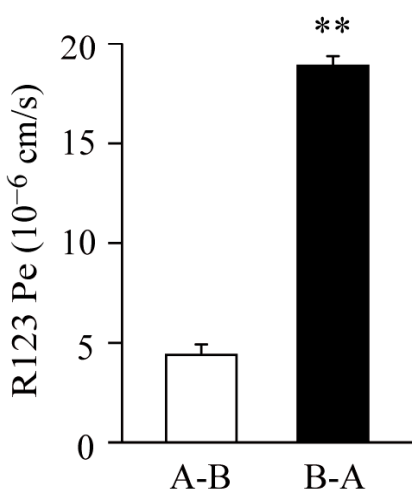

Figure 2. (a) Expression of transporters on monkey brain endothelial cells using PCR analysis; (b) Expression of efflux transporters ABCB1 and ABCG2 detected by western blot; (c) Functional analysis of ABCB1 using rhodamine 123 (R123) accumulation assay (left) and bi-directional transport of R123 (right). Accumulation of R123 was increased by ABCB1 inhibitor (cyclosporin; $10 \mu \mathrm{M}$ ). Transport of R123 in the basolateral to apical (B-A) was greater than apical to basolateral (A-B). Values presented are means \pm SEM $\left(n=3-4{ }^{* *} p<0.01\right)$.

\subsection{Effect of Astrocytes on Barrier Function of Monkey Brain Endothelial Cells}

Primary monkey and rat astrocytes stained for glial fibrillary acidic protein showed a branched, stellate morphology (Figure 3). In a non-contact co-culture for 5 days the TEER values of monkey BECs were increased by rat primary astrocytes from neonatal animals, but not by monkey astrocytes isolated from adult animals (Figure 3b). For further experiments rat astrocytes and brain pericytes were used. 
$\mathbf{a}$
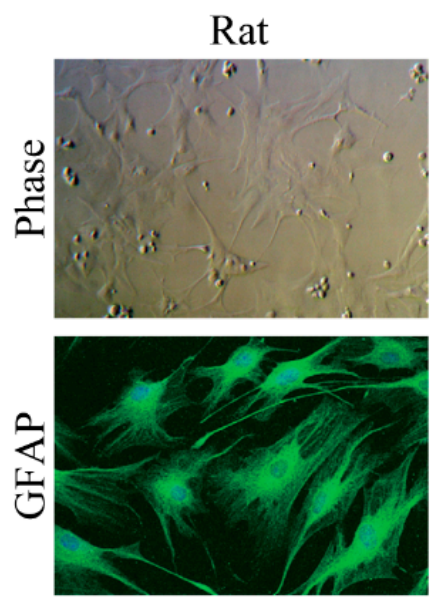
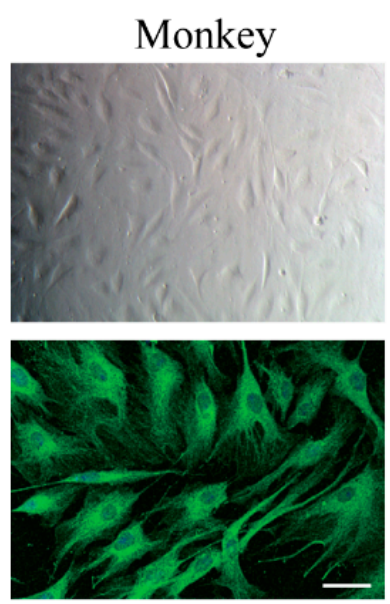

b

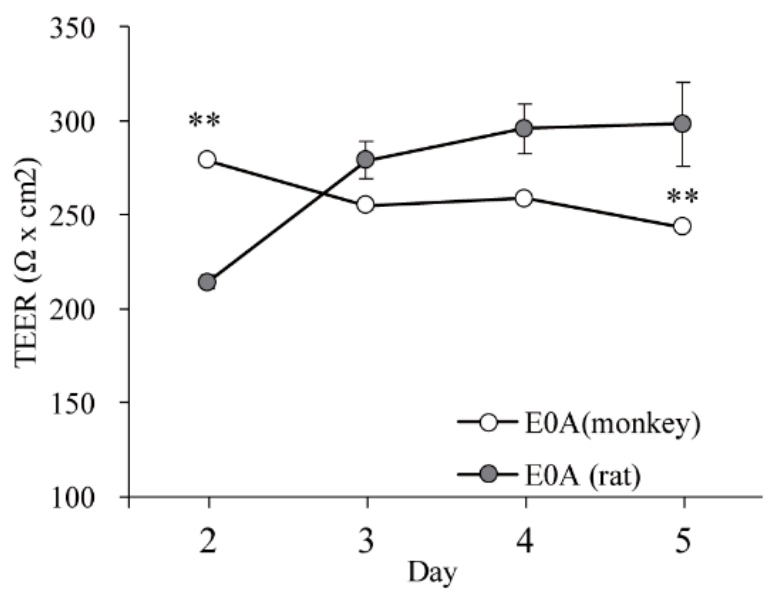

Figure 3. (a) Characterization of primary monkey astrocytes by immunofluorescence microscopy. Both monkey and rat astrocytes express glial fibrillary acidic protein (GFAP). Cell nuclei were counterstained with TO-PRO-3 (blue). Bar $=50 \mu \mathrm{m}$; (b) Barrier function of the co-culture BBB models with astrocytes. BECs from monkey were co-cultured with astrocytes from either monkey (E0A (monkey)) or rat (E0A (rat)). Barrier function was assessed by measuring TEER. Values presented are means \pm SEM. $\left(n=3,{ }^{* *} p<0.01\right)$. E00: monkey brain endothelial monolayers; E0A: co-culture of monkey brain endothelial cells and astrocytes (rat or monkey).

\subsection{Barrier Integrity of Different BBB Models}

The investigated barrier functions of MBECs in mono- and different co-culture settings, TEER, and permeability for fluorescein were measured (Figure 4a,b).

Astrocytes and pericytes, which surround brain capillaries in vivo, contribute to the formation and maintenance of a functional BBB. Four types of in vitro BBB models were made from MBECs, primary rat astrocytes, and rat pericytes. The electrical resistance of MBEC monolayers (E00) stayed below $100 \Omega \times \mathrm{cm}^{2}$ during the investigated 6-day period, while both rat primary astrocytes (E0A) and brain pericytes (EP0) significantly elevated the TEER values. The biggest effect on the paracellular tightness of MBECs was seen in the EPA co-culture model (545 $\pm 40 \Omega \times \mathrm{cm}^{2}$ at day 4$)$, when both cell types were present (Figure $4 a$ ). The permeability of the monolayer MBEC model (E00; $2.44 \pm 0.04 \times 10^{-6} \mathrm{~cm} / \mathrm{s}$ ) for fluorescein was the highest as compared to the co-culture models (Figure $4 \mathrm{~b}$ ). The lowest Na-F permeability was measured when brain pericytes were present in the co-culture models either alone (EP0; $0.74 \pm 0.06 \times 10^{-6} \mathrm{~cm} / \mathrm{s}$ ) or together with astrocytes $\left(\mathrm{EPA} ; 0.69 \pm 0.07 \times 10^{-6} \mathrm{~cm} / \mathrm{s}\right)$. The tightening effects of rat astrocytes and pericytes on the paracellular barrier of MBECs was demonstrated at the level of TJ proteins as well (Figure 4c). The expression of integral membrane TJ proteins claudin- 5 and occludin were elevated in all three co-culture models as compared to the MBEC mono-cultures (E00), while the level of TJ linker protein ZO-1 was increased only in the EPA model (Figure 4c). 

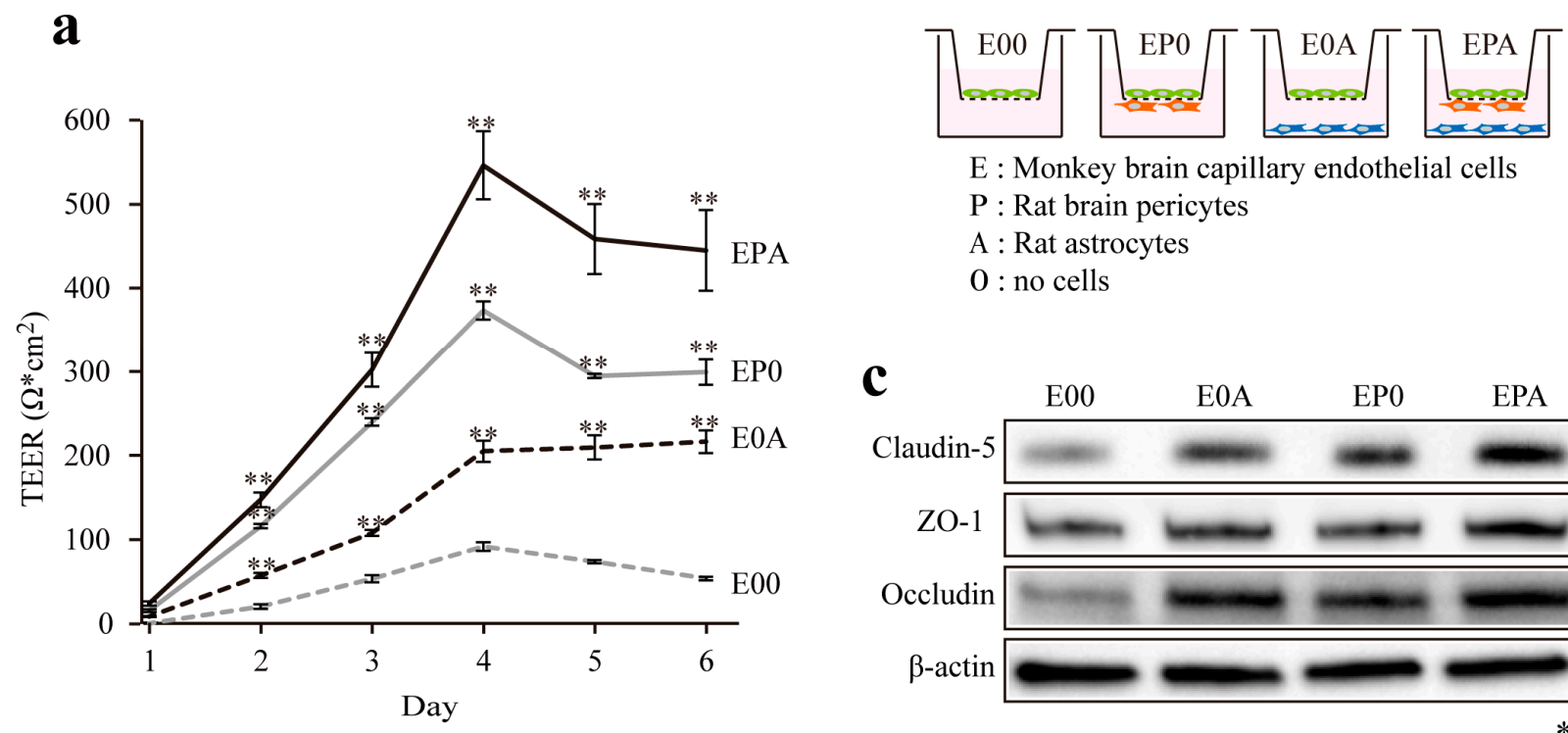

E : Monkey brain capillary endothelial cells

$\mathrm{P}$ : Rat brain pericytes

A : Rat astrocytes

$0:$ no cells
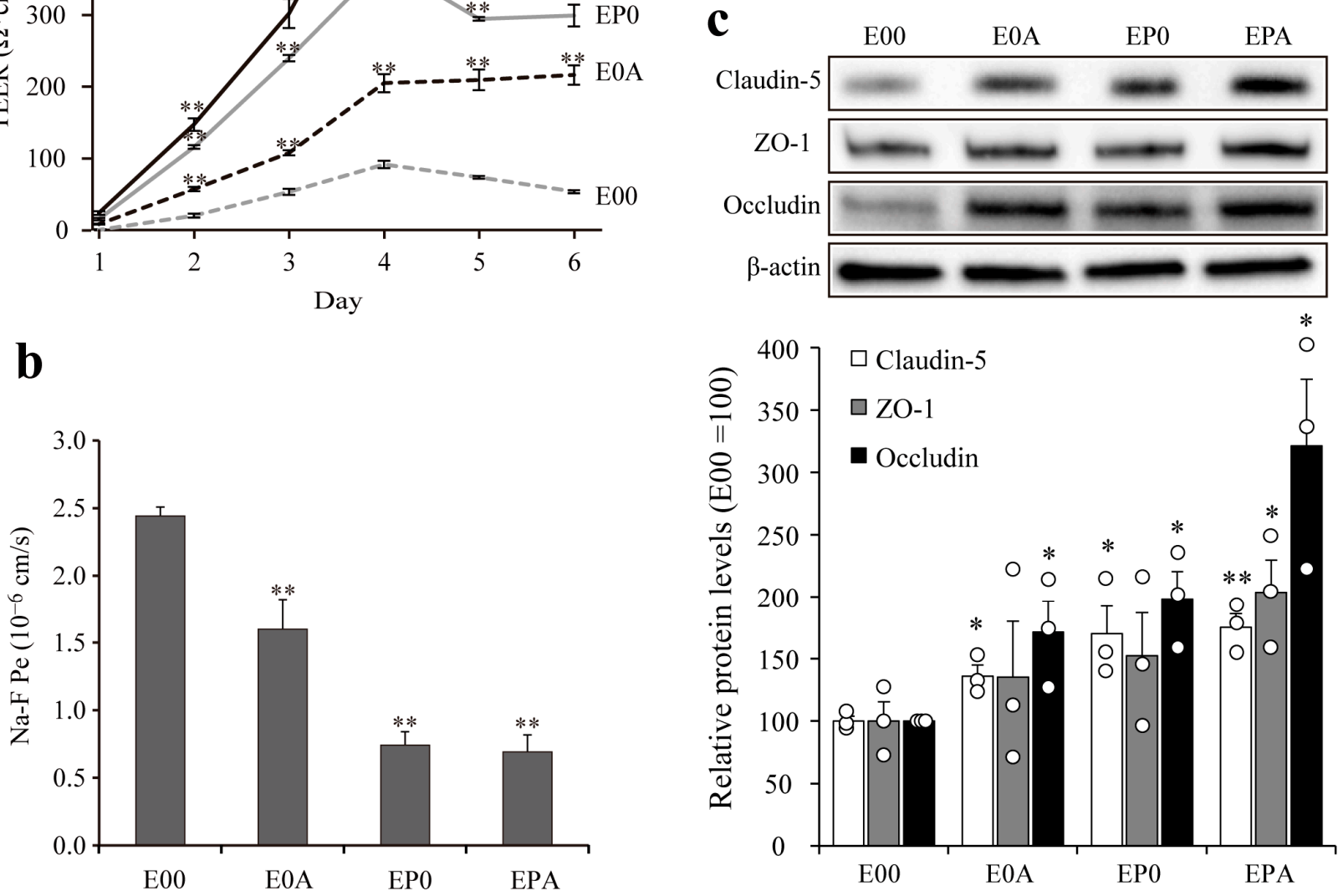

Figure 4. Comparison of the barrier properties of BBB mono- and co-culture models. Barrier function of different BBB models prepared from brain endothelial cells $(\mathrm{E})$, astrocytes $(\mathrm{A})$, and pericytes $(\mathrm{P})$ were measured by (a) transendothelial electrical resistance (TEER, expressed as $\Omega \times \mathrm{cm}^{2}$ ) and (b) endothelial permeability coefficient for sodium fluorescein (Na-F $\mathrm{P}_{\mathrm{e}}$, expressed in $\left.10^{-6} \mathrm{~cm} / \mathrm{s}\right)$. Data are presented as means $\pm \mathrm{SEM}\left(\mathrm{n}=3,{ }^{* *} p<0.01 \mathrm{vs}\right.$. E00); (c) Expression of the tight junction proteins ZO-1, occludin, and claudin-5 in different BBB models detected by western blot. The relative level of the proteins was determined by densitometry. Data are presented as means $\pm \operatorname{SEM}\left(\mathrm{n}=3,{ }^{*} p<0.05,{ }^{* *} p<0.01\right.$ vs. E00).

\subsection{Expression of Transporters on Different BBB Models}

The expression of key ABC and SLC transporter genes were determined in MBEC mono- and co-culture models (Figure 5). In the case of efflux transporters P-gp (ABCB1) and $\mathrm{BCRP}(\mathrm{ABCG})$ an increase in the gene expression was observed by astrocytes (E0A), but not by other co-culture models (Figure $5 \mathrm{a}, \mathrm{b}$ ). Co-culture conditions did not change the expression of ABCC1, 2, 4, 5 genes in MBECs (Supplementary Figure S2). 
a
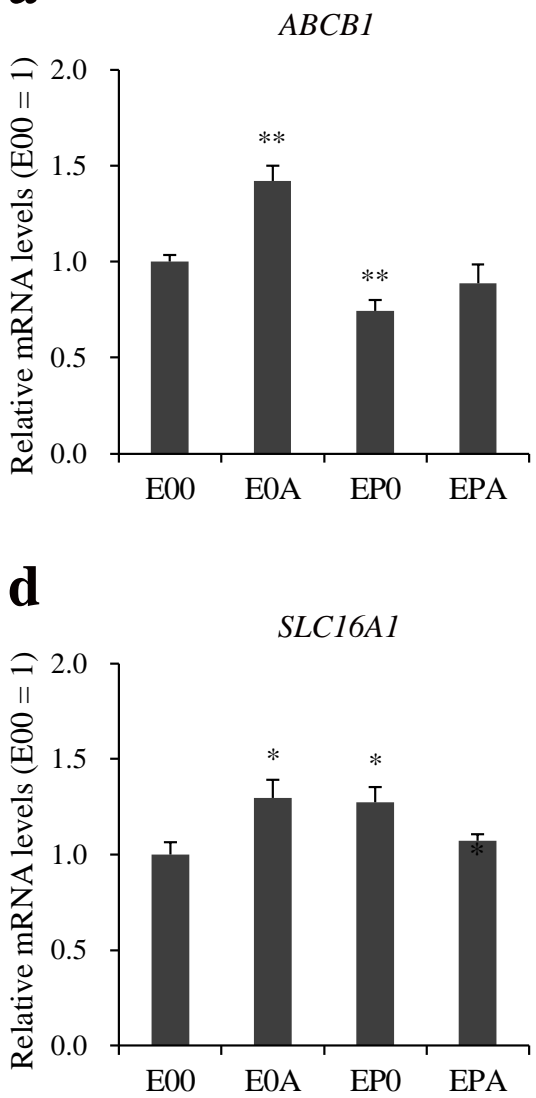

b
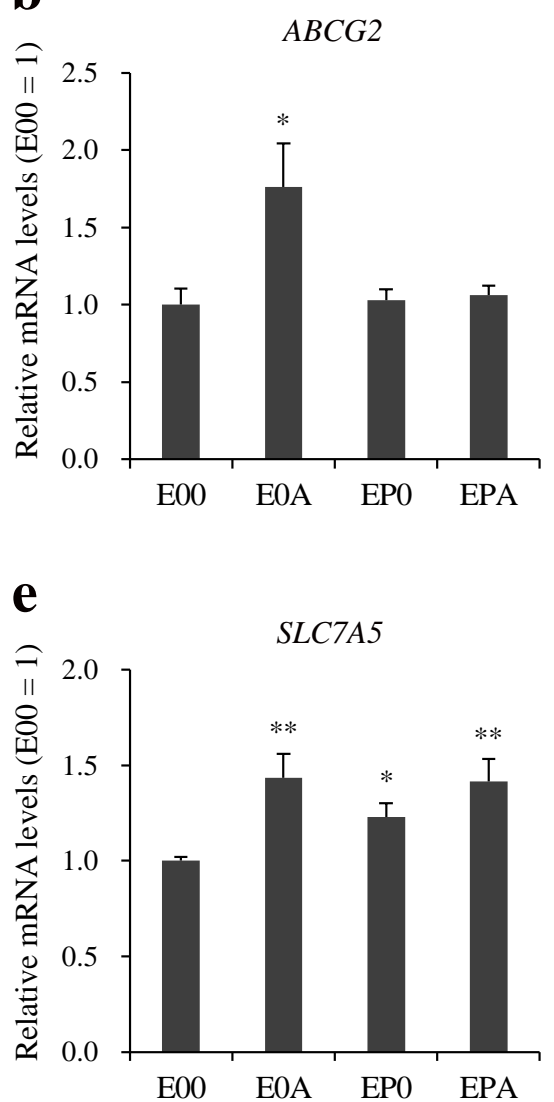

C
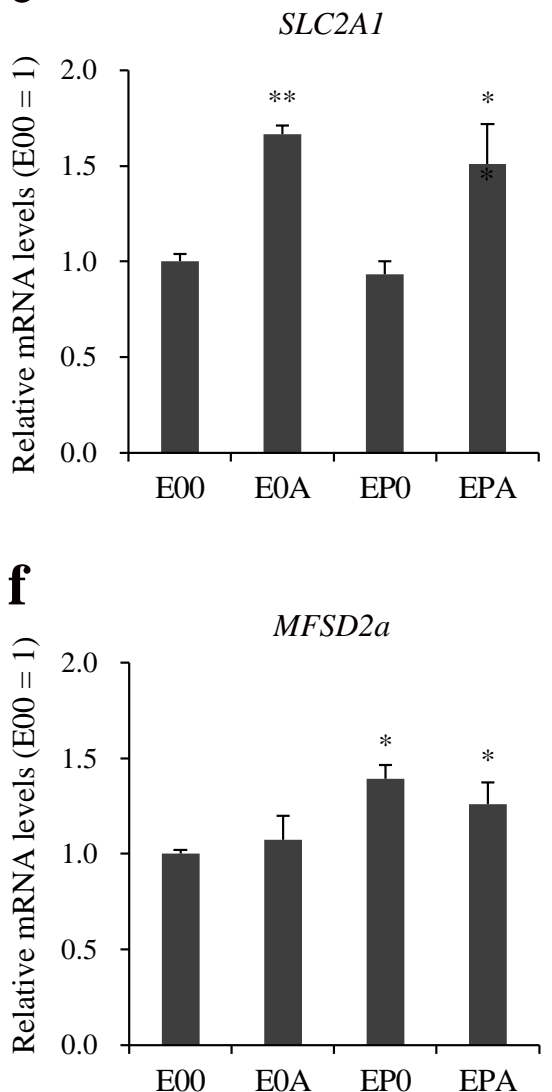

Figure 5. Expression of transporter genes (a) ABCB1; (b) ABCG2; (c) SLC2A1; (d) SLC16A1; (e) SLC7A5; and (f) MFSD2A in different BBB models. Expression of transporters were determined by quantitative PCR. All data are presented as means \pm $\operatorname{SEM}\left(\mathrm{n}=4-9,{ }^{*} p<0.05,{ }^{* *} p<0.01\right.$ vs. E00).

Among the three SLC transporter genes, elevated expression of GLUT-1 was seen in MBECs in the EOA and EPA models (Figure 5c), while the level of MCT-1 was increased in the E0A and EP0 BBB models (Figure 5d) as compared to the monolayers cultured alone. The expression of LAT-1 gene was elevated in all three co-culture setups (Figure 5e). The gene expression of the lipid transporter MFSD2A was higher in MBECs (Figure 5f) when pericytes were present in the co-culture models (EP0 and EPA).

The gene expression results were verified by western blot (Figure 6). The expression of GLUT-1 protein in MBECs was increased by co-culture with rat astrocytes either alone (E0A) or in the presence of rat pericytes (EPA; Figure 6b), while only astrocytes could elevate the expression of P-gp (Figure $6 \mathrm{c}$ ) and BCRP (Figure $6 \mathrm{~d}$ ) as compared to mono-cultures of MBECs (E00).

3.6. Correlation between Permeability of Drugs Tested in Rat and Monkey BBB Co-Culture Models, and Mouse In Vivo Model

To investigate the differences in drug permeability between the monkey and rat in vitro co-culture (EPA) models, permeability tests were performed for 10 well known pharmacological compounds with different transport mechanisms (Table 2) used in our previous studies $[8,15]$. Caffeine, antipyrin, and indomethacin, lipophilic compounds with passive transcellular flux across the $\mathrm{BBB}$, showed the highest $\mathrm{P}_{\text {app }}$ values for both the monkey and rat in vitro BBB models. The permeability values of the efflux pump ligands verapamil, loperamide and quinidine were also in the same range and decreasing order in the culture models. 
$\mathbf{a}$

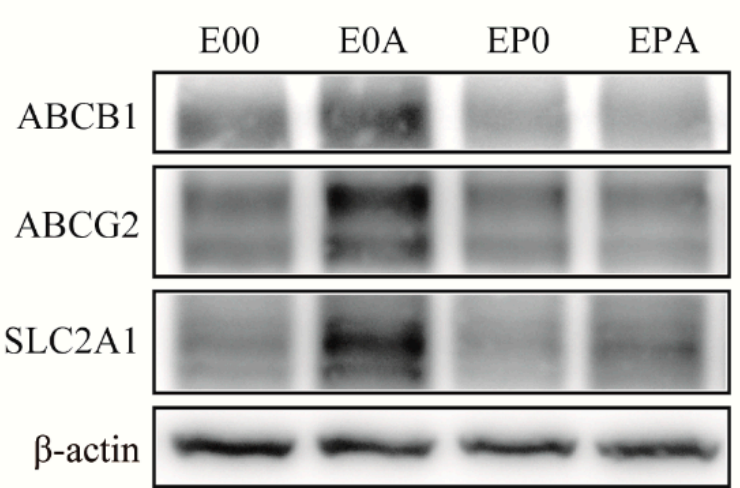

C

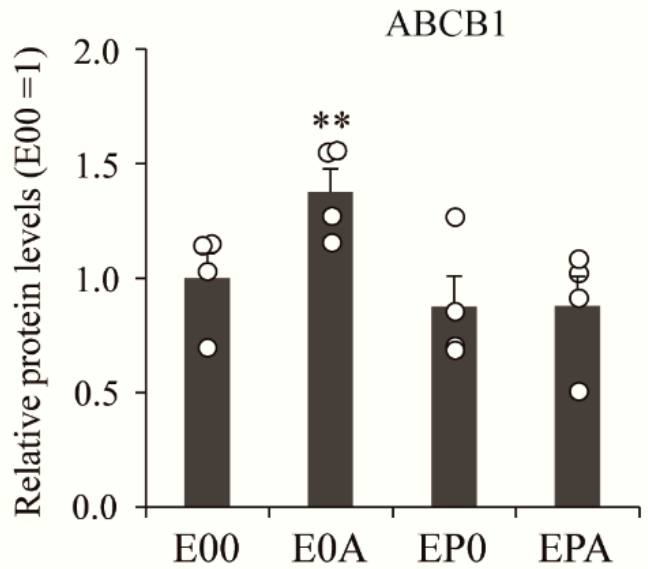

b SLC2A1

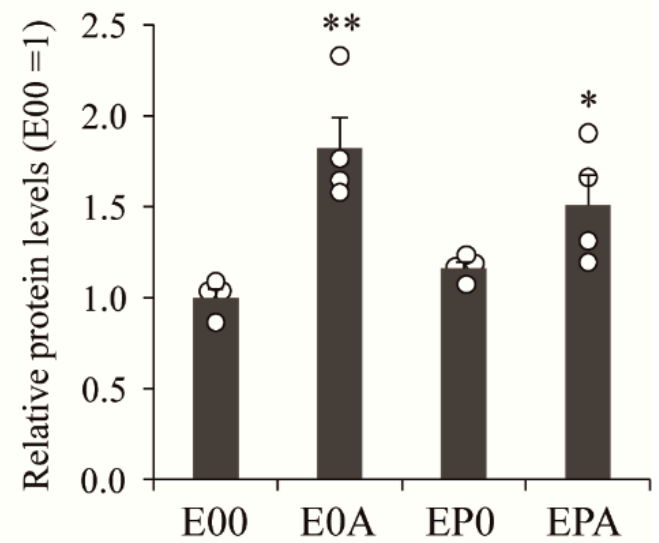

d

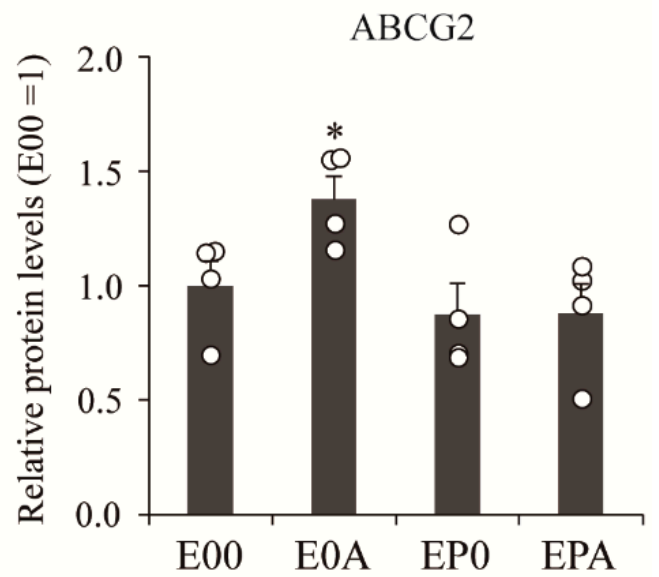

Figure 6. Expression of transporters in different BBB models were determined by western blot. (a) Representative image of the western blot. The bar graph reflects the quantitative analysis of the expression levels of SLC2A1 (b), ABCB1 (c), and ABCG2 (d) were determined in the different BBB models. All data are presented as means \pm SEM $(n=4, * p<0.05$, ** $p<0.01$ vs. E00).

Table 2. BBB permeability parameters measured in monkey and rat in vitro models and in mouse in vivo.

\begin{tabular}{|c|c|c|c|c|c|c|c|c|}
\hline \multirow[t]{2}{*}{ Compound } & \multirow{2}{*}{$\begin{array}{c}\text { Primary } \\
\text { Transport } \\
\text { Mechanism }\end{array}$} & \multicolumn{3}{|c|}{ Monkey BBB } & \multicolumn{3}{|c|}{ Rat BBB * } & \multirow{2}{*}{$\begin{array}{c}\begin{array}{c}\text { Mouse In } \\
\text { Vivo * }\end{array} \\
P_{\text {app }} \\
\left(\times 10^{-6} \mathrm{~cm} / \mathrm{s}\right)\end{array}$} \\
\hline & & $\begin{array}{c}P_{\text {app }} \text { A-B } \\
\left(\times 10^{-6} \mathrm{~cm} / \mathrm{s}\right)\end{array}$ & $\begin{array}{c}P_{\text {app }} \text { B-A } \\
\left(\times 10^{-6} \mathrm{~cm} / \mathrm{s}\right)\end{array}$ & EffluxRatio & $\begin{array}{c}P_{\text {app }} \text { A-B } \\
\left(\times 10^{-6} \mathrm{~cm} / \mathrm{s}\right)\end{array}$ & $\begin{array}{c}P_{\text {app }} \text { B-A } \\
\left(\times 10^{-6} \mathrm{~cm} / \mathrm{s}\right)\end{array}$ & EffluxRatio & \\
\hline Caffeine & $\mathrm{PT} / \mathrm{CMT}$ & 60.53 & 65.25 & 1.08 & 64.95 & 59.91 & 0.92 & 11.11 \\
\hline Antipyrin & PT & 48.06 & 47.07 & 0.98 & 51.78 & 45.38 & 0.88 & 10.75 \\
\hline Indomethacin & PT & 32.70 & 39.11 & 1.20 & 33.63 & 44.07 & 1.31 & 0.13 \\
\hline Verapamil & $\mathrm{PT} / \mathrm{E}$ & 20.10 & 29.86 & 1.49 & 23.38 & 31.82 & 1.38 & 5.69 \\
\hline Loperamide & $\mathrm{PT} / \mathrm{E}$ & 9.16 & 16.26 & 1.78 & 15.57 & 21.76 & 1.47 & 1.05 \\
\hline Quinidine & $\mathrm{PT} / \mathrm{E}$ & 6.01 & 10.33 & 1.74 & 6.28 & 12.11 & 1.93 & 1.69 \\
\hline Cimetidine & E & 3.00 & 2.88 & 0.97 & 3.86 & 2.80 & 0.75 & 0.20 \\
\hline Digoxin & $\mathrm{E}$ & 2.25 & 3.34 & 1.49 & 1.25 & 3.07 & 2.47 & 0.10 \\
\hline Vinblastine & E & 1.47 & 2.14 & 1.46 & 2.42 & 1.39 & 0.69 & 1.43 \\
\hline Atenolol & $\mathrm{PP} / \mathrm{E}$ & 4.60 & 3.43 & 0.83 & 1.36 & 2.26 & 1.71 & 0.23 \\
\hline
\end{tabular}

* Data are obtained from [15]. Abbreviations: CMT, carrier mediated transport; E, efflux transport; PP, passive paracellular; PT, passive transcellular; $\mathrm{P}_{\text {app }}$, apparent permeability coefficient; $\mathrm{P}_{\text {app }} \mathrm{A}-\mathrm{B}, \mathrm{P}_{\text {app }}$ measured in apical to basal (luminal to abluminal) direction, $\mathrm{P}_{\text {app }} \mathrm{B}-\mathrm{A}$, $\mathrm{P}_{\mathrm{app}}$ measured in basal to apical (abluminal to luminal) direction.

The compounds showing the lowest $\mathrm{P}_{\text {app }}$ values were cimetidine, digoxin, vinblastine, and atenolol in both in vitro BBB models with slight differences in the ranking. The 
penetration of atenolol and digoxin was the two lowest in the rat in vitro and mouse in vivo models, while digoxin and vinblastine were the two compounds with the slowest permeability in the monkey model (Table 2).

When the $\mathrm{P}_{\text {app }}$ data measured in the A-B direction on the monkey BBB model were compared with the rat in vitro data, a high correlation $\left(R^{2}=0.88\right)$ was found (Figure 7a). The correlation between $P_{\text {app }}$ data measured in the B-A direction was even higher $\left(R^{2}=0.98\right)$ when the rat and monkey co-culture BBB models were compared (Figure $7 \mathrm{~b}$ ). The lowest correlation $\left(R^{2}=0.66\right)$ was found between $P_{\text {app }}$ values measured in the monkey in vitro $\mathrm{BBB}$ model and in vivo data obtained in mice (Figure 7c) indicating species differences in transporter activities.

$\mathbf{a}$

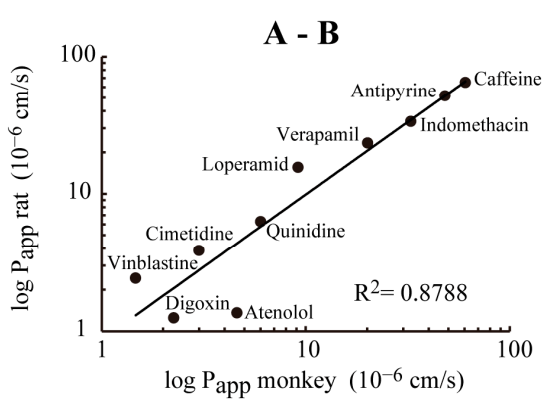

b

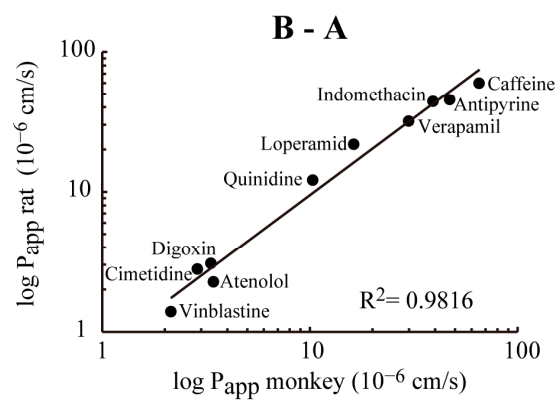

C

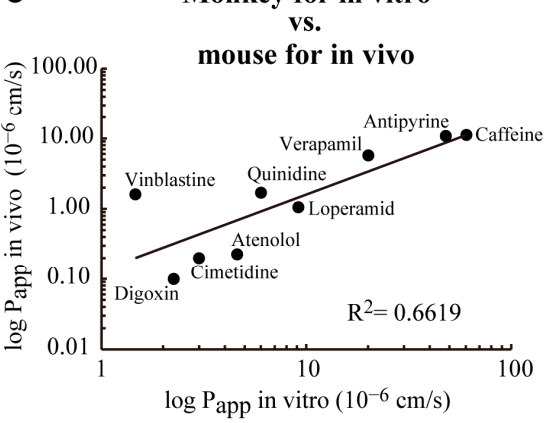

Figure 7. Correlation between permeability (Papp) data of drugs tested in in vitro rat BBB model, in vitro monkey BBB model, and mouse in vivo model. (a) Correlation between permeability of drugs in the apical to basolateral (A-B) tested at rat $\mathrm{BBB}$ model and monkey BBB model; (b) Correlation between permeability of drugs in the basolateral to apical (B-A) tested at rat BBB model and monkey BBB model; (c) Correlation between permeability of drugs tested at monkey BBB model (Papp in vitro) and the permeability of the same drugs measured in animal models (Papp in vivo).

\subsection{Effect of TGF- $\beta 1$ on Barrier Integrity in the Monkey Co-Culture BBB Model}

To further prove the functionality of the monkey BBB co-culture model, the effects of the cytokine transforming growth factor $\beta 1$ (TGF- $\beta 1$ ) was tested on the barrier integrity (Figure 8$)$. In the TGF- $\beta 1(1 \mathrm{ng} / \mathrm{mL})$ treated group a $~ 30 \%$ decrease in TEER values was measured at the 3,6 , and 12-h time points as compared to the medium treated group (Figure 8a). A similar effect on the barrier integrity was seen for 6-h TGF- $\beta 1$ treatment in the concentration range of $0.1-10 \mathrm{ng} / \mathrm{mL}$ (Figure $8 \mathrm{~b}$ ).

$\mathbf{a}$

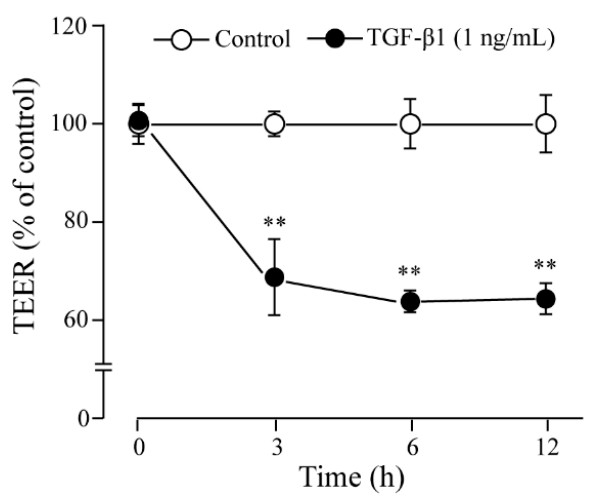

b

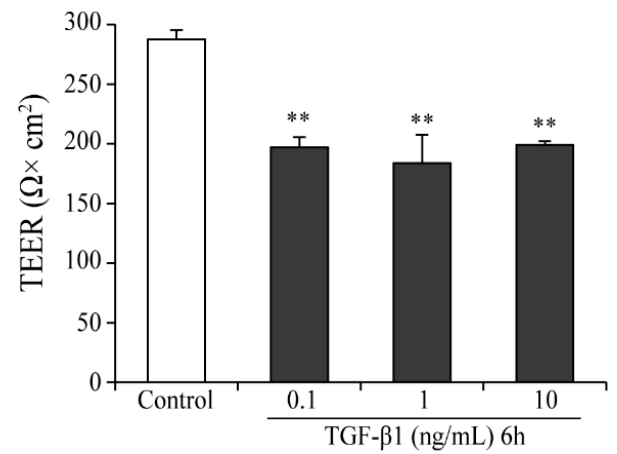

Figure 8. Effect of TGF- $\beta 1$ on barrier integrity in the monkey co-culture BBB model (EPA). (a) Effect of TGF- $\beta 1$ on the barrier integrity assessed by transendothelial electrical resistance (TEER) followed up to $12 \mathrm{~h}$; (b) Effect of different concentrations of TGF- $\beta 1$ on the TEER (6-h treatment). All data are presented as means $\pm \operatorname{SEM}\left(\mathrm{n}=3{ }^{* *} p<0.01\right.$ vs. control). 


\section{Discussion}

Cell-culture models are versatile tools to examine the molecular basis of the functions of brain endothelial cells in physiological and pathological conditions including drug transport $[1,2,16]$. The applicability of these systems in drug discovery depends on how well they can predict brain penetration in vivo [5]. While there are efforts to establish human cell-based BBB models for drug transport studies, no models fulfill all the validation criteria [17]. Species differences has been described in absolute protein expression levels of transporters in human, monkey, and mouse brain capillaries [12] confirming previous functional data. Among different species used in preclinical drug investigations, primates were found to be closest to humans in terms of BBB transport of P-gp ligands [18]. Culture models are important to replace, reduce, and refine experiments using animals, in line with the $3 \mathrm{R}$ principle. In the present study, a non-human primate co-culture BBB model consisting of primary monkey brain capillary endothelial cells, rat pericytes, and astrocytes was developed and characterized.

\subsection{Characterization of the Primary Triple-Co-Culture Primate BBB Model}

Primary cultures of cerebral endothelial cells, despite showing lower expression levels for some TJ, transporter, or receptor genes as compared to freshly isolated capillaries, still retain many of the in vivo properties, as it has been demonstrated for several species [3,6], including monkey cerebral endothelial cells [19]. The isolation and culture of monkey cerebral endothelial cells (Macaca rhesus) has been described 20 years ago [20,21]. This BBB model, the co-culture of monkey brain endothelial cells and monkey astrocytes, was characterized for immunological properties and used to study changes after simian immunodeficiency virus infection [22] or cytokine treatments [23]. In a recent study, the transcriptome of cerebral endothelial cells from Macaca fascicularis was compared between freshly isolated cells and cells kept in culture conditions [19]. The key elements of BBB functions, namely barrier integrity and control of molecular trafficking, were well preserved in MBECs in culture [19].

In our study, brain capillary endothelial cells isolated from Macaca fascicularis obtained by the puromycin selection method [14] expressed the most important transmembrane TJ proteins claudin-5, occludin and ZO-1, key solute and nutrient transporters and active efflux pumps $\mathrm{ABCB} 1$ and $\mathrm{ABCG} 2$ at the $\mathrm{BBB}$, and showed a polarized transport of the P-gp ligand R123 (Figures 1 and 2). The expression of the BBB transporters and TJ proteins are in concordance with previous works on monkey brain endothelial cultures $[19,20]$, while the functional measurement of efflux pump activity is well supported by in vivo measurements [18].

To improve the paracellular barrier properties of the BBB model, MBECs were cocultured with astrocytes isolated from adult monkey or rat neonatal brain cortex. Rat astrocytes increased the TEER of monkey brain endothelial cell layers in a time-dependent way, indicating tightened interendothelial junctions, in concordance with similar observations on rat, bovine, porcine and human cerebral endothelial cells [3]. Although the initial TEER of MBECs was high in the presence of monkey astrocytes, this effect did not last and the barrier inducing effect was lower than in the case of rat neonatal astroglia cultures (Figure 3). In a study comparing the gene expression of freshly isolated adult astrocytes with cultured adult and cultured neonatal astrocytes from rats, neonatal astrocytes expressed the highest levels for several growth factor genes, including basic fibroblast growth factor (FGF2) [24]. Since FGF2 [25] and other glia-derived growth factors tighten the barrier properties of BBB culture models [1], the higher expression of growth factors in neonatal rat astrocyte cultures as compared to adult monkey astrocyte cultures can explain the TEER differences. Brain pericytes also enhanced the TEER and decreased the permeability of MBECs layers, and the effect was even greater in the presence of both cell types (Figure 4), similarly to observations on rat brain endothelial cell models [10]. Astrocytes increased the expression of $\mathrm{ABCB} 1$ and $\mathrm{ABCG} 2$ at gene and protein levels, while the expression of GLUT1 was elevated in all co-culture models (Figures 5 and 6). Our results show that 
astrocytes, pericytes, and their combination do not uniformly increase the level of different influx and efflux transporters, but a complex pattern of regulation is seen, which is in agreement with findings on porcine brain endothelial models [26].

The permeability of 10 selected pharmacons was tested on the monkey EPA model and compared to data measured on our rat EPA BBB model (Table 2, Figure 7). While a high correlation $\left(R^{2}=0.8788\right)$ was obtained when the permeability data from the monkey model were compared with the rat BBB model, the $\mathrm{P}_{\mathrm{app}}$ values of atenolol and digoxin, ligands of human P-gp [27], were higher in the monkey model. The correlation of the in vitro data obtained on the monkey model with in vivo data obtained in mice was lower $\left(R^{2}=0.6619\right)$, partly due to these two ligands. Our observation indicates that for some substrates of P-glycoprotein rat brain capillary endothelial cells have higher P-gp activity than monkey endothelial cells. Indeed, lower expression of P-glycoprotein was found in monkey and human brain capillaries than in mouse brain capillaries by a quantitative targeted absolute proteomics method [12]. In addition, a PET study demonstrated that penetration of P-gp substrates, such as [ $\left.{ }^{11} \mathrm{C}\right]$ GR205171, was greater into human and monkey brain than into rodent brain [18]. The protein expression levels of P-gp, BCRP, and MRP4 efflux transporters were similar in isolated human and monkey brain capillaries, only OATP1A2, expressed at low level in monkey brain capillaries, was under detection limit in human samples [12]. The present findings agree with these observations and suggest that the triple co-culture model using monkey endothelial cells can be a useful model to predict the brain penetration of P-gp ligands.

To test the applicability of the model to study pathological conditions, we have treated the EPA BBB model with TGF- $\beta 1$ and found that this cytokine significantly decreases the TEER of the model, indicating paracellular opening (Figure 8). Similar effects were seen in bovine brain endothelial cells [1]. Our finding, together with observations on cytokine treatments and virus infection [22,23], indicate that the monkey model could be also used for the study of inflammatory conditions related to the BBB.

We should also note, that the limitations of primary cell based primate co-culture BBB models include that they are more expensive than cell line models, the isolation process is lengthy and need technical expertise, and tissue availability may depend on geographical location, ethical regulations, and permissions.

\subsection{Application of the Primary Triple-Co-Culture Primate BBB Model}

Since the preliminary publications about our model $[28,29]$ a ready to use in vitro BBB model made of primary cultures of monkey (Macaca fascicularis) brain capillary endothelial cells, rat brain pericytes and astrocytes have been commercially available at PharmaCo-Cell Co. Ltd. (Nagasaki, Japan) [30]. This primary triple co-culture non-human primate BBB model has been widely used for various biomedical and pharmaceutical applications, and some results have been already published during recent years [31-39].

Our primate BBB model has been successfully applied for testing the BBB penetration of novel nonpeptidic human immunodeficiency virus type 1 (HIV-1) protease inhibitors and selecting drug candidates with promising brain-targeting properties $[31,32,34,36]$. Permeability data across the monkey $\mathrm{BBB}$ model were provided not only for novel nonpeptidic HIV-1 protease inhibitor compounds GRL-083-13, GRL-084-13, and GRL-087-13 (mean $P_{\text {app }}$ values in the 55.5 to $72.0 \times 10^{-6} \mathrm{~cm} / \mathrm{s}$ range), but also for known conventional anti-HIV-1 drugs, including protease inhibitors saquinavir, amprenavir, lopinavir, and darunavir (mean $\mathrm{P}_{\text {app }}$ values in the 4.9 to $15.4 \times 10^{-6} \mathrm{~cm} / \mathrm{s}$ range); nucleoside reverse transcriptase inhibitors $3^{\prime}$-azido-2 ${ }^{\prime}, 3^{\prime}$-dioxythymidine, lamivudine, tenofovir disoproxil fumarate and emtricitabine (mean $P_{\text {app }}$ values in the 9.2 to $23.2 \times 10^{-6} \mathrm{~cm} / \mathrm{s}$ range); nonnucleoside reverse transcriptase inhibitors nevirapine and efavirenz (mean $P_{\text {app }}$ values are 32.0 and $14.4 \times 10^{-6} \mathrm{~cm} / \mathrm{s}$, respectively); integrase inhibitors raltegravir and elvitegravir (mean $\mathrm{P}_{\text {app }}$ values are 10.2 and $18.6 \times 10^{-6} \mathrm{~cm} / \mathrm{s}$, respectively); and C-C chemokine receptor type 5 (CCR5) inhibitor maraviroc (mean $P_{\text {app }}$ value is $16.0 \times 10^{-6} \mathrm{~cm} / \mathrm{s}$ ) [36]. Permeability data for reference drug with high brain penetration, caffeine $\left(\mathrm{P}_{\mathrm{app}}=71.7 \pm 3.2 \times 10^{-6} \mathrm{~cm} / \mathrm{s}\right)$, 
and passive paracellular marker sucrose $\left(\mathrm{P}_{\mathrm{app}}=1.0 \pm 0.3 \times 10^{-6} \mathrm{~cm} / \mathrm{s}\right)$ measured in this experiment [36] confirm the adequacy of the model system for testing in vitro penetration of drug candidates targeted to the central nervous system (CNS) [3]. These data are also in accordance with our data set shown in Table 2 and Figure 7.

The model was also used to test the BBB permeability of a natural compound, myricetin, a polyphenolic flavonoid, beneficial in the prevention of amyloid $\beta_{1-42}$ peptideinduced neuronal cell damage, and a $P_{\text {app }}$ value of $2.5 \times 10^{-6} \mathrm{~cm} / \mathrm{s}$ was measured [38]. Furthermore, the functional expression the drug transporter SLC35F2 (solute carrier family 35 member F2) was demonstrated using our in vitro BBB model [39]. In this study, the quality of the monkey BBB kits was validated by low paracellular permeability (TEER value of $330 \Omega \times \mathrm{cm}^{2}$ and low Lucifer yellow transport) and active efflux transport of P-glycoprotein substrate quinidine [39]. Cultured monkey brain endothelial cells expressed SLC35F2 transporter mRNA and protein, and transport experiments confirmed famotidineinhibitable BBB permeability and intraendothelial accumulation of YM155 (sepantronium bromide), an SLC35F2 substrate [39].

This in vitro BBB model was also applied to prove that oxytocin is transported to the CNS by receptors for advanced glycation end-product (RAGE) [37]. Dose-dependent bloodto-brain direction transport of oxytocin was reduced by approximately $70 \%$ in monkey brain endothelial cell monolayers when RAGE was silenced by shRNA, while TEER values of $800 \Omega \times \mathrm{cm}^{2}$ were unchanged in knockout cells [37].

Four types of monoclonal antibodies specific to the extracellular domains of human claudin-5 (anti-CLDN-5 mAb) dose-dependently attenuated TEER and increased the BBB permeability for Na-F and fluorescein isothiocyanate-labeled dextran (MW: $4 \mathrm{kDa}$ ) in our triple culture monkey model [35]. The efficacy of R9, the most potent anti-CLDN-5 mAb selected on the in vitro primate model, has been recently confirmed in vivo, and $3 \mathrm{mg} / \mathrm{kg}$ intravenous dose resulted in increased BBB permeability to Na-F in male cynomolgous monkeys (Macaca fascicularis) indicating that claudin- 5 may be a potential target to increase CNS drug delivery in humans [40]

In addition, an in vitro cancer metastasis model was established using our monkey BBB model [33]. Extracellular vesicles derived from human breast cancer cells deteriorated BBB properties (reduced TEER and increased $\mathrm{P}_{\text {app }}$ for sodium fluorescein) through the change in actin dynamics in vitro and promoted metastatic transport of cancer cells to the abluminal space [33]. It was proved that microRNA-181c promoted the dysfunction of BBB through delocalization of actin fiber via the downregulation of 3-phosphoinositidedependent protein kinase-1 (PDPK1) [33]. The applicability of the presented non-human primate model in a wide variety of biomedical and drug discovery experiments and the consistency of permeability data accumulated at various laboratories strengthen the claim that the ready-to-use monkey BBB kits are suitable for academic research and the pharmaceutical industry.

\section{Conclusions}

We have developed and characterized a non-human primate co-culture BBB model using primary monkey brain endothelial cells, rat brain pericytes, and astrocytes. Monkey brain endothelial cells in the presence of both pericytes and astrocytes expressed enhanced barrier properties and elevated levels of key BBB influx and efflux transporters. A good correlation was found between the endothelial permeability coefficients of 10 well known drugs in the monkey and rat BBB culture models. A lower correlation was found between the permeability values of the drug set when the monkey culture model was compared to mouse in vivo data, indicating transporter differences between species. The characterized monkey BBB model has been applied in several biomedical and drug discovery studies and can be a valuable tool for basic and applied pharmaceutical research. 
Supplementary Materials: The following are available online at https:/ / www.mdpi.com/article/10 .3390/pharmaceutics13091484/s1, Supplementary Method: Culture of rat brain capillary pericytes, Culture of rat cerebral astrocytes, Table S1: Antibodies used for immunohistochemistry and western blot, Figure S1: Expression of ABCC transporters in different BBB models. Figure S2. Expression of ABCC transporter genes in different BBB models determined by quantitative PCR. (a) Expression of ABCC1 transporter; (b) Expression of ABCC2 transporter; (c) Expression of ABCC4 transporter; (d) Expression of ABCC4 transporter. All data are presented as means \pm SEM ( $n=5-7, * p<0.05$ vs. E00). E00: monkey brain endothelial monolayers; E0A: co-culture of monkey brain endothelial cells and rat astrocytes; EP0: co-culture of monkey brain endothelial cells and rat brain pericytes; EPA: co-culture of monkey brain endothelial cells and rat astrocytes and rat brain pericytes.

Author Contributions: Conceptualization, M.N., S.N. and D.W.; data curation, D.W. and S.N.; formal analysis, D.W. and S.N.; methodology, D.W., S.N., Y.M., A.E.T., M.V. and M.A.D.; investigation, D.W., S.N., Y.M., A.E.T. and M.V.; resources, J.A., M.V. and M.N.; supervision, M.V., J.A., M.N. and M.A.D.; funding acquisition, J.A. and M.N.; writing—original draft preparation, S.N. and M.A.D.; writing-review and editing, D.W., S.N., Y.M., A.E.T., M.V., J.A., M.N. and M.A.D. All authors have read and agreed to the published version of the manuscript.

Funding: This research was funded by JSPS KAKENHI grant number 22590243 (to M.N.), by the Japan Society for the Promotion of Science (JSPS) grant number 20K09394 (to S.N.), by JSPS and the Hungarian Academy of Sciences under the Japan-Hungary Research Cooperative Program (to Y.M. and M.A.D.), Grants-in-Aid for Scientific Research (Fostering Joint International Research) grant number 20KK0254 (to Y.M.).

Institutional Review Board Statement: The study was conducted according to the guidelines of the Declaration of Helsinki. Based on the Guide for the Care and Use of Laboratory Animals from the Ministry of Education, Culture, Sports, Science, and Technology, Japan, all experimental procedures were reviewed by Institutional Animal Care and Use Committee of Nagasaki University and finally approved by the University's president (license No.: 1805011452, date of approval: 1 May 2018).

Informed Consent Statement: Not applicable.

Data Availability Statement: The data presented in this study are available on request from the corresponding author.

Conflicts of Interest: M.N. is president, D.W. is director, M.A.D. is senior consultant of PharmaCoCell Co. Ltd., Nagasaki, Japan. The company had no role in the design of the study; in the collection, analyses, or interpretation of data; in the writing of the manuscript, or in the decision to publish the results. The authors declare no other conflict of interest.

\section{References}

1. Deli, M.A.; Ábrahám, C.S.; Kataoka, Y.; Niwa, M. Permeability studies on in vitro blood-brain barrier models: Physiology, pathology, and pharmacology. Cell. Mol. Neurobiol. 2005, 25, 59-127. [CrossRef]

2. Cecchelli, R.; Berezowski, V.; Lundquist, S.; Culot, M.; Renftel, M.; Dehouck, M.P.; Fenart, L. Modelling of the blood-brain barrier in drug discovery and development. Nat. Rev. Drug Discov. 2007, 6, 650-661. [CrossRef]

3. Helms, H.C.; Abbott, N.J.; Burek, M.; Cecchelli, R.; Couraud, P.O.; Deli, M.A.; Förster, C.; Galla, H.J.; Romero, I.A.; Shusta, E.V.; et al. In vitro models of the blood-brain barrier: An overview of commonly used brain endothelial cell culture models and guidelines for their use. J. Cereb. Blood Flow Metab. 2016, 36, 862-890. [CrossRef]

4. Tóth, A.; Veszelka, S.; Nakagawa, S.; Niwa, M.; Deli, M.A. Patented in vitro blood-brain barrier models in CNS drug discovery. Recent Pat. CNS Drug Discov. 2011, 6, 107-118. [CrossRef]

5. Avdeef, A.; Deli, M.A.; Neuhaus, W. In vitro assays for assessing BBB permeability: Artificial membrane and cell culture models. In Blood-Brain Barrier in Drug Discovery: Optimizing Brain Exposure of CNS Drugs and Minimizing Brain Side Effects; Di, L., Kerns, E.H., Eds.; John Wiley \& Sons, Inc: Hoboken, NJ, USA, 2015; pp. 188-237, ISBN 978-1-118-78835-6. [CrossRef]

6. Veszelka, S.; Tóth, A.; Walter, F.R.; Tóth, A.E.; Gróf, I.; Mészáros, M.; Bocsik, A.; Hellinger, E.; Vastag, M.; Rákhely, G.; et al. Comparison of a rat primary cell-based blood-brain barrier model with epithelial and brain endothelial cell lines: Gene expression and drug transport. Front. Mol. Neurosci. 2018, 11, 166. [CrossRef] [PubMed]

7. Banks, W.A. From blood-brain barrier to blood-brain interface: New opportunities for CNS drug delivery. Nat. Rev. Drug Discov. 2016, 15, 275-292. [CrossRef]

8. Nakagawa, S.; Deli, M.A.; Nakao, S.; Honda, M.; Hayashi, K.; Nakaoke, R.; Kataoka, Y.; Niwa, M. Pericytes from brain microvessels strengthen the barrier integrity in primary cultures of rat brain endothelial cells. Cell. Mol. Neurobiol. 2007, 27, 687-694. [CrossRef] 
9. Nakagawa, S.; Deli, M.A.; Kawaguchi, H.; Shimizudani, T.; Shimono, T.; Kittel, Á.; Tanaka, K.; Niwa, M. A new blood-brain barrier model using primary rat brain endothelial cells, pericytes and astrocytes. Neurochem. Int. 2009, 54, 253-263. [CrossRef]

10. Sweeney, M.D.; Zhao, Z.; Montagne, A.; Nelson, A.R.; Zlokovic, B.V. Blood-brain barrier: From physiology to disease and back. Physiol. Rev. 2019, 99, 21-78. [CrossRef]

11. Ito, K.; Uchida, Y.; Ohtsuki, S.; Aizawa, S.; Kawakami, H.; Katsukura, Y.; Kamiie, J.; Terasaki, T. Quantitative membrane protein expression at the blood-brain barrier of adult and younger cynomolgus monkeys. J. Pharm. Sci. 2011, 100, 3939-3950. [CrossRef]

12. Ohtsuki, S.; Uchida, Y.; Kubo, Y.; Terasaki, T. Quantitative targeted absolute proteomics-based ADME research as a new path to drug discovery and development: Methodology, advantages, strategy, and prospects. J. Pharm. Sci. 2011, 100, 3547-3559. [CrossRef] [PubMed]

13. Lu, T.M.; Houghton, S.; Magdeldin, T.; Durán, J.G.B.; Minotti, A.P.; Snead, A.; Sproul, A.; Nguyen, D.T.; Xiang, J.; Fine, H.A.; et al. Pluripotent stem cell-derived epithelium misidentified as brain microvascular endothelium requires ETS factors to acquire vascular fate. Proc. Natl. Acad. Sci. USA 2021, 118, e2016950118. [CrossRef]

14. Perrière, N.; Demeuse, P.; Garcia, E.; Regina, A.; Debray, M.; Andreux, J.P.; Couvreur, P.; Scherrmann, J.M.; Temsamani, J.; Couraud, P.O.; et al. Puromycin-based purification of rat brain capillary endothelial cell cultures. Effect on the expression of blood-brain barrier-specific properties. J. Neurochem. 2005, 93, 279-289. [CrossRef]

15. Hellinger, É.; Veszelka, S.; Tóth, A.E.; Walter, F.; Kittel, Á.; Bakk, M.L.; Tihanyi, K.; Háda, V.; Nakagawa, S.; Duy, T.D.H.; et al. Comparison of brain capillary endothelial cell-based and epithelial (MDCK-MDR1, Caco-2, and VB-Caco-2) cell-based surrogate blood-brain barrier penetration models. Eur. J. Pharm. Biopharm. 2012, 82, 340-351. [CrossRef]

16. Campos-Bedolla, P.; Walter, F.R.; Veszelka, S.; Deli, M.A. Role of the blood-brain barrier in the nutrition of the central nervous system. Arch. Med. Res. 2014, 45, 610-638. [CrossRef]

17. Morofuji, Y.; Nakagawa, S. Drug development for central nervous system diseases using in vitro blood-brain barrier models and drug repositioning. Curr. Pharm. Des. 2020, 26, 1466-1485. [CrossRef]

18. Syvänen, S.; Lindhe, O.; Palner, M.; Kornum, B.R.; Rahman, O.; Långström, B.; Knudsen, G.M.; Hammarlund-Udenaes, M. Species differences in blood-brain barrier transport of three positron emission tomography radioligands with emphasis on P-glycoprotein transport. Drug Metab. Dispos. 2009, 37, 635-643. [CrossRef] [PubMed]

19. Chaves, C.; Do, T.M.; Cegarra, C.; Roudières, V.; Tolou, S.; Thill, G.; Rocher, C.; Didier, M.; Lesuisse, D. Non-human primate blood-brain barrier and in vitro brain endothelium: From transcriptome to the establishment of a new model. Pharmaceutics 2020, 12, 967. [CrossRef]

20. MacLean, A.G.; Orandle, M.S.; Alvarez, X.; Williams, K.C.; Lackner, A.A. Rhesus macaque brain microvessel endothelial cells behave in a manner phenotypically distinct from umbilical vein endothelial cells. J. Neuroimmunol. 2001, 118, 223-232. [CrossRef]

21. MacLean, A.G.; Orandle, M.S.; MacKey, J.; Williams, K.C.; Alvarez, X.; Lackner, A.A. Characterization of an in vitro rhesus macaque blood-brain barrier. J. Neuroimmunol. 2002, 131, 98-103. [CrossRef]

22. MacLean, A.G.; Rasmussen, T.A.; Bieniemy, D.N.; Alvarez, X.; Lackner, A.A. SIV-induced activation of the blood-brain barrier requires cell-associated virus and is not restricted to endothelial cell activation. J. Med. Primatol. 2004, 33, 236-242. [CrossRef] [PubMed]

23. Sansing, H.A.; Renner, N.A.; MacLean, A.G. An inverted blood-brain barrier model that permits interactions between glia and inflammatory stimuli. J. Neurosci. Methods 2012, 207, 91-96. [CrossRef] [PubMed]

24. Nakagawa, T.; Schwartz, J.P. Gene expression patterns in in vivo normal adult astrocytes compared with cultured neonatal and normal adult astrocytes. Neurochem. Int. 2004, 45, 203-242. [CrossRef] [PubMed]

25. Toyoda, K.; Tanaka, K.; Nakagawa, S.; Thuy, D.H.; Ujifuku, K.; Kamada, K.; Hayashi, K.; Matsuo, T.; Nagata, I.; Niwa, M. Initial contact of glioblastoma cells with existing normal brain endothelial cells strengthen the barrier function via fibroblast growth factor 2 secretion: A new in vitro blood-brain barrier model. Cell. Mol. Neurobiol. 2013, 33, 489-501. [CrossRef]

26. Thomsen, L.B.; Burkhart, A.; Moos, T. A triple culture model of the blood-brain barrier using porcine brain endothelial cells, astrocytes and pericytes. PLOS ONE 2015, 10, e0134765. [CrossRef]

27. Saaby, L.; Helms, H.C.; Brodin, B. IPEC-J2 MDR1, a Novel High-Resistance Cell Line with Functional Expression of Human P-glycoprotein (ABCB1) for Drug Screening Studies. Mol. Pharm. 2016, 13, 640-652. [CrossRef]

28. Nakagawa, S.; Deli, M.A.; Thuy, D.H.D.; Sagara, M.; So, G.; Yamada, N.; Tatsumi, R.; Tanaka, K.; Niwa, M. An in vitro monkey BBB model. J. Pharmacol. Sci. 2010, 112, 91.

29. Watanabe, S.; Nakagawa, S.; Deli, M.A.; Izawa, K.; Aruga, J.; Niwa, M. A new primate in vitro blood-brain barrier model using primary monkey capillary cells. J. Pharmacol. Sci. 2017, 133, S236.

30. BBB Kit ${ }^{\mathrm{TM}}$ (MBT-24H)/(MBT-24F). Available online: https://www.pharmacocell.co.jp/en/products/mbt24h_e.html (accessed on 16 June 2021).

31. Salcedo, G.P.M.; Amano, M.; Yashchuk, S.; Mizuno, A.; Das, D.; Ghosh, A.K.; Mitsuya, H. GRL-04810 and GRL-05010, difluoridecontaining nonpeptidic HIV-1 protease inhibitors (PIs) that inhibit the replication of multi-PI-resistant HIV-1 in vitro and possess favorable lipophilicity that may allow blood-brain barrier penetration. Antimicrob. Agents Chemother. 2013, 57, 6110-6121. [CrossRef] 
32. Amano, M.; Tojo, Y.; Salcedo-Gómez, P.M.; Parham, G.L.; Nyalapatla, P.R.; Das, D.; Ghosh, A.K.; Mitsuya, H. A novel tricyclic ligand-containing nonpeptidic HIV-1 protease inhibitor, GRL-0739, effectively inhibits the replication of multidrugresistant HIV-1 variants and has a desirable central nervous system penetration property in vitro. Antimicrob. Agents Chemother. 2015, 59, 2625-2635. [CrossRef]

33. Tominaga, N.; Kosaka, N.; Ono, M.; Katsuda, T.; Yoshioka, Y.; Tamura, K.; Lötvall, J.; Nakagama, H.; Ochiya, T. Brain metastatic cancer cells release microRNA-181c-containing extracellular vesicles capable of destructing blood-brain barrier. Nat. Commun. 2015, 6, 6716. [CrossRef]

34. Amano, M.; Salcedo-Gómez, P.M.; Zhao, R.; Yedidi, R.S.; Das, D.; Bulut, H.; Delino, N.S.; Sheri, V.R.; Ghosh, A.K.; Mitsuya, H. A modified P1 moiety enhances in vitro antiviral activity against various multidrug-resistant HIV-1 variants and in vitro central nervous system penetration properties of a novel nonpeptidic protease inhibitor, GRL-10413. Antimicrob. Agents Chemother. 2016, 60, 7046-7059. [CrossRef]

35. Hashimoto, Y.; Shirakura, K.; Okada, Y.; Takeda, H.; Endo, K.; Tamura, M.; Watari, A.; Sadamura, Y.; Sawasaki, T.; Doi, T.; et al. Claudin-5-binders enhance permeation of solutes across the blood-brain barrier in a mammalian model. J. Pharmacol. Exp. Ther. 2017, 363, 275-283. [CrossRef]

36. Amano, M.; Salcedo-Gómez, P.M.; Yedidi, R.S.; Zhao, R.; Hayashi, H.; Hasegawa, K.; Nakamura, T.; Martyr, C.D.; Ghosh, A.K.; Mitsuya, $\mathrm{H}$. Novel central nervous system (CNS)-targeting protease inhibitors for drug-resistant HIV infection and HIV-associated CNS complications. Antimicrob. Agents Chemother. 2019, 63, e00466-19. [CrossRef]

37. Yamamoto, Y.; Liang, M.; Munesue, S.; Deguchi, K.; Harashima, A.; Furuhara, K.; Yuhi, T.; Zhong, J.; Akther, S.; GGoto, H.; et al. Vascular RAGE transports oxytocin into the brain to elicit its maternal bonding behaviour in mice. Commun. Biol. 2019, 2, 76. [CrossRef]

38. Kimura, A.M.; Tsuji, M.; Yasumoto, T.; Mori, Y.; Oguchi, T.; Tsuji, Y.; Umino, M.; Umino, A.; Nishikawa, T.; Nakamura, S.; et al. Myricetin prevents high molecular weight $\mathrm{A} \beta_{1-42}$ oligomer-induced neurotoxicity through antioxidant effects in cell membranes and mitochondria. Free Radic. Biol. Med. 2021, 171, 232-244. [CrossRef]

39. Mochizuki, T.; Mizuno, T.; Kurosawa, T.; Yamaguchi, T.; Higuchi, K.; Tega, Y.; Nozaki, Y.; Kawabata, K.; Deguchi, Y.; Kusuhara, H. Functional investigation of solute carrier family 35, member F2, in three cellular models of the primate blood-brain barrier. Drug Metab. Dispos. 2021, 49, 3-11. [CrossRef]

40. Tachibana, K.; Hashimoto, Y.; Shirakura, K.; Okada, Y.; Hirayama, R.; Iwashita, Y.; Nishino, I.; Ago, Y.; Takeda, H.; Kuniyasu, H.; et al. Safety and efficacy of an anti-claudin- 5 monoclonal antibody to increase blood-brain barrier permeability for drug delivery to the brain in a non-human primate. J. Control Release 2021, 336, 105-111. [CrossRef] 